\title{
Predictive Value of Rotterdam Score and Marshall Score in Traumatic Brain Injury: A Contemporary Review
}

\author{
Rakesh Mishra ${ }^{1}$ Harold Enrique Vasquez Ucros ${ }^{2,3}$ \\ Luis Rafael Moscote-Salazar ${ }^{6}$ Md. Moshiur Rahman \\ ${ }^{1}$ Department of Neurosurgery, Institute of Medical Sciences, \\ Banaras Hindu University, Varanasi, Uttar Pradesh, India \\ ${ }^{2}$ Department of Medicina General, Universidad del Sinú - Elias \\ Bechara Zainúm de Cartagena, Cartagena, Colombia \\ ${ }^{3}$ Jefe de Investigacion ENCEPHALOS en Consejo LatinoAmericano de \\ Neurointensivismo-CLaNi, Cartagena, Colombia \\ ${ }^{4}$ Department of Medicina General, Universidad Surcolombiana, \\ Medico Investigador Consejo Latinoamericano de \\ Neurointensivismo - CLaNi, Clinica Sahagún IPS SA, Cordoba, \\ Columbia \\ ${ }^{5}$ Department of Medicina Intensiva, Epidemiologia Clinica, Intensive \\ Care Research (GRICIO), Universidad de Cartagena, Corporacion \\ Universitaria Rafael Nuñez, Cartagena, Colombia \\ ${ }^{6}$ Department of Neurosurgery, University of Cartagena, Cartagena \\ de Indias, Colombia \\ ${ }^{7}$ Department of Neurosurgery, Holy Family Red Crescent Medical \\ College, Dhaka, Bangladesh \\ ${ }^{8}$ Department of Neurosurgery, All India Institute of Medical \\ Sciences, Bhopal, Madhya Pradesh, India
}

William Andres Florez-Perdomo ${ }^{4 \odot}$ José Rojas Suarez ${ }^{5}$ Amit Agrawal ${ }^{80}$

Indian J Neurotrauma 2022;19:69-77.

\author{
Address for correspondence Amit Agrawal, MCh, Department of \\ Neurosurgery, All India Institute of Medical Sciences, Saket Nagar, \\ Bhopal 462020, Madhya Pradesh, India \\ (e-mail: dramitagrawal@gmail.com).
}

\begin{abstract}
Keywords

- scoring systems

- traumatic brain injury

- Rotterdam score

- Marshall score

- CT-based scoring
\end{abstract}

This article conducts a contemporary comparative review of the medical literature to update and establish evidence as to which framework among Rotterdam and Marshall computed tomography (CT)-based scoring systems predicts traumatic brain injury (TBI) outcomes better. The scheme followed was following the recommendations of the Preferred Reporting Items for Systematic Reviews and Meta-Analysis guidelines for literature search. The search started on August 15, 2020 and ended on December 31, 2020. The combination terms used were Medical Subject Headings terms, combination keywords, and specific words used for describing various pathologies of TBI to identify the most relevant article in each database. PICO question to guide the search strategy was: "what is the use of Marshall (I) versus Rotterdam score (C) in TBI patients (P) for mortality risk stratification (0)." The review is based on 46 references which included a full review of 14 articles for adult TBI patients and 6 articles for pediatric TBI articles comparing Rotterdam and Marshall CT scores. The review includes 8,243 patients, of which 2,365 were pediatric and 5,878 were adult published online April 15, 2021
DOI https://doi.org/ 10.1055/s-0041-1727404 ISSN 0973-0508
(C)2021. Neurotrauma Society of India.

This is an open access article published by Thieme under the terms of the Creative Commons Attribution-NonDerivative-NonCommercial-License, permitting copying and reproduction so long as the original work is given appropriate credit. Contents may not be used for commercial purposes, or adapted, remixed, transformed or built upon. (https://creativecommons.org/licenses/by-nc-nd/4.0/).

Thieme Medical and Scientific Publishers Pvt. Ltd. A-12, 2nd Floor, Sector 2, Noida-201301 UP, India 
TBI patients. Marshall CT classification is not ordinal, is more descriptive, has better inter-rater reliability, and poor performance in a specific group of TBI patients requiring decompressive craniectomy. Rotterdam CT classification is ordinal, has better discriminatory power, and a better description of the dynamics of intracranial changes. The two scoring systems are complimentary. A combination of clinical parameters, severity, ischemic and hemodynamic parameters, and CT scoring system could predict the prognosis of TBI patients with significant accuracy. None of the classifications has good evidence for use in pediatric patients.

\section{Introduction}

Traumatic brain injury (TBI) is a leading cause of morbidity and mortality in trauma patients and is a major public health concern globally by affecting the younger age group. ${ }^{1-5}$ Clinical outcomes of TBI is multifactorial and varies across institutions, regions, age groups, and health care systems. ${ }^{4}$ Due to the malignant nature of TBI, various prediction and prognostic models are in use for resource allocation, prediction of clinical outcome at the time of admission, decision making, and family counseling. ${ }^{6,7}$ Results of the IMPACT study group showed that computed tomography (CT) characteristics have highest prognostic value after clinical severity. ${ }^{8}$ Marshall (1995) and Rotterdam CT (2005) scoring systems are two most commonly used to predict clinical outcome in TBI patients. ${ }^{7,9,10}$ Recently, many studies were conducted to evaluate the comparative efficacy of the two prediction models..$^{5,711-14}$ Each of these models aims at improving the outcome prediction and has their own sets of limitations. Since guidelines for surgery in TBI patients is not uniform worldwide, two major limitations of Marshall scoring is stated as the division of hematoma based on volume and surgical evacuation. ${ }^{15}$ Additionally, there is existing literature in favor of either of the scoring system and there is no conclusive evidence as to which scoring systems has better predictive power. Therefore, this comparative review aims to summarize and update the available evidence from existing studies of the predictive value of Marshall and Rotterdam CT scoring system in predicting clinical outcome in TBI patients.

\section{Methods}

We conducted this comparative review based on the Preferred Reporting Items for Systematic Reviews and Meta-Analysis ${ }^{16}$ statement guidelines to ensure a high-quality study. A systematic and comprehensive literature search was conducted in the electronic database of PubMed and Scopus to identify cohort, prospective, observational studies, and randomized clinical trials (RCTs) on validation of Rotterdam score and Marshall score for mortality risk stratification within 6 months in TBI patients. The search started on August 15, 2020 and ended on December 31, 2020. The combination terms used were Medical Subject Headings (MeSH) terms, combination keywords, and specific words used for describing various pathologies of TBI to identify the most relevant article in each database. PICO question to guide the search strategy was: "what is the use of Marshall (I) versus Rotterdam score (C) in TBI patients (P) for mortality risk stratification (0)." An example of the search strategy used in PubMed was: "patients"[All Fields])) AND ("paediatrics"[All Fields] OR "pediatrics"[MeSH Terms] OR "pediatrics"[All Fields]) AND ("child"[MeSH Terms] OR “child"[All Fields] OR "children"[All Fields]) AND ("traumatic brain injury" [MeSH Terms] OR "traumatic brain injury" [All fields]) AND ("mortality risk stratification" [All fields]) OR ("Rotterdam score" [All Fields] OR "Marshall score" [All fields]) NOT ("Helsinki score" [MeSH Terms] OR "Helsinki score" [All Fields]). All patients included were diagnosed by CT scans. Studies with pediatrics patients and studies on the scoring system other than Marshall and Rotterdam CT scoring system were excluded from this review. Articles were reviewed by two authors to identify studies in which patients with TBI were diagnosed by CT and mortality risk stratification was performed by Marshall and Rotterdam score. Authors independently reviewed initially titles and abstracts and then full texts of remaining articles and results. The references were studied to identify other prospective studies. No assessment of quality and risk of bias was done and no study was excluded based on quality.

\section{Results}

This review is based on a comparison of the predictive value of Rotterdam ${ }^{13}$ and Marshall ${ }^{10} \mathrm{CT}$ score in predicting clinical outcome in TBI patients (- Table 1). A total of $63(n=63)$ studies were retrieved using the search criteria and screened for potential eligibility. The studies comparing the predictive value of two scoring systems or assessment of the scoring system in the pediatric age group were considered for this review. This review was based on 46 referenced article, including 14 citations on comparison of the two scoring system and 6 citations on use of Rotterdam and Marshall CT scoring system in pediatric TBI patients. There were no systematic review, meta-analysis, or RCT found. The review includes 8,243 patients, of which 2,365 were pediatric and 5,878 were adult TBI patients. Characteristics of studies including adult patients and pediatric patients are as shown in - Table 2, respectively. 


\section{Discussion}

\section{Prediction Models in TBI}

TBI accounts for significant mortality, morbidity, and economic burden globally. ${ }^{3}$ It was found in a systematic review that economically productive young age group have a particularly high incidence of TBI. ${ }^{2}$ On the other hand, individuals in extremes of age sustaining TBI have more severe injuries and the likelihood of poorer outcomes. ${ }^{2}$ Several classification systems are in use to classify TBI based on clinical and radiological parameters. These classification systems aim to prognosticate the outcomes of TBI. However, there is no classification system which is comprehensive and inclusive of all predictors. Clinical complications of a TBI can lead from a compressive brain syndrome, and consequently, intracranial hypertension. Massive hemorrhage depending on the degree of TBI may end in hypovolemic shock and worsen the prognosis of patients. Therefore, it is important to have a scale that correctly classifies the prognosis of patients with TBI and thus be able to take the correct measurements. Mayo classification system devised a classification for TBI with a sensitivity of $89 \%$ and specificity of $98 \%$ by including multiple predictors in the classification system. ${ }^{25}$ Clinically, Glasgow Coma Scale (GCS) and Glasgow Outcome Scale (GOS) are used to assess the severity and prognosticate brain injury. ${ }^{26,27}$ However, it is difficult and, in some cases, impossible to determine GCS, since many patients are intubated, sedated, intoxicated, or unable to speak or move. ${ }^{25-28}$ Therefore, CT is the recommended evaluation method of choice. In 1991, an image prognostic scale was first described by Marshall et al,

Table 1 Differences between Marshall and Rotterdam CT classification

\begin{tabular}{|c|c|c|}
\hline S. No. & Marshall CT classification & $\begin{array}{l}\text { Rotterdam CT } \\
\text { classification }\end{array}$ \\
\hline 1. & More descriptive & More discriminative \\
\hline 2. & $\begin{array}{l}\text { Lacks individual CT } \\
\text { characteristics }\end{array}$ & $\begin{array}{l}\text { Individual CT } \\
\text { characteristics present }\end{array}$ \\
\hline 3. & $\begin{array}{l}\text { Predictive value is similar to } \\
\text { Rotterdam CT score }\end{array}$ & $\begin{array}{l}\text { Predictive value is } \\
\text { similar to Marshall CT } \\
\text { score }\end{array}$ \\
\hline 4. & Higher inter-rater reliability & $\begin{array}{l}\text { Comparatively less } \\
\text { inter-rater reliability }\end{array}$ \\
\hline 5. & $\begin{array}{l}\text { Uncertain predictive } \\
\text { value in patients requiring } \\
\text { decompressive craniectomy }\end{array}$ & $\begin{array}{l}\text { Better predictive } \\
\text { value in patients } \\
\text { requiring decompres- } \\
\text { sive craniectomy }\end{array}$ \\
\hline 6. & $\begin{array}{l}\text { Individual parameter of } \\
\text { mass lesion evacuated/non } \\
\text { evacuated is retrospective } \\
\text { and hence has variable } \\
\text { application }\end{array}$ & $\begin{array}{l}\text { No such restriction on } \\
\text { individual parameters } \\
\text { measured }\end{array}$ \\
\hline 7. & $\begin{array}{l}\text { Patients with lower GCS are } \\
\text { likely to have grade IV or V } \\
\text { and hence no significant } \\
\text { discriminatory predictive } \\
\text { value in these cases }\end{array}$ & $\begin{array}{l}\text { Prognosis can be } \\
\text { discriminated even in } \\
\text { patients with low GCS } \\
\text { based on individual CT } \\
\text { characteristics }\end{array}$ \\
\hline 8. & Not ordinal & Ordinal \\
\hline
\end{tabular}

Abbreviations: CT, computed tomography; GCS, Glasgow coma scale. according to many characteristics assessed in CT brain. ${ }^{29}$ This classification system is considered a gold standard in TBI classification. International guidelines on the prognosis of severe TBI states class I evidence for Marshall ${ }^{10} \mathrm{CT}$ scoring as a major CT prognostic model in TBI patients. ${ }^{30}$ However, it has limitations for space-occupying injuries., ${ }^{9,1020,31}$ Accordingly, in 2005, Maas et al determined a new prognostic classification by imaging that includes basal cisterns, midline, epidural hematoma, intraventricular, or subarachnoid hemorrhage (SAH), generating greater validation to define the mortality risk stratification or prognosis. ${ }^{9}$ One of the major differences between these two classifications is that Rotterdam CT classification is stand-alone and does not require any intervention as one of the parameters in contrast to Marshall score where evacuation of mass lesion is one of the measurements. The predictive power of these scoring systems depends on the outcome measured. Both the scoring system has a similar mortality prediction but only Rotterdam scoring correlation with predicted outcome measured as GOS. ${ }^{17}$ Also, none of the two scorings were found to have significant predictive power for outcome evaluated as Functional Independence Measure motor or cognitive domain at discharge or 9 months' follow-up, though specific scores (Marshall 3 and 5 , Rotterdam 5 and 6 ) were able to predict these outcomes and length of stay. ${ }^{19}$ This study aimed to conduct a comparative review to establish the existing evidence for the predictive power of Rotterdam and Marshall scoring system in mortality risk stratification of TBI patients.

\section{Predictive Value of Rotterdam CT Scoring System}

Mohammadifard et al $^{15}$ conducted a comparative study of Marshall and Rotterdam scoring system in predicting early deaths after brain trauma in a cohort of 150 patients. Mean age was $43.36 \pm 21.65$ years, mean GCS was $8.7 \pm 3$, and mean Marshall and Rotterdam CT score was $3.2 \pm 1.3$ and $2.5 \pm 1.0$, respectively, in this study. ${ }^{15}$ They found a significant correlation between the Rotterdam score and mortality at 2 weeks, 1 month, and after 3 months; however, no such correlation was found with Marshall score. ${ }^{15}$ Sensitivity and specificity for mortality prediction at 2 weeks for Rotterdam and Marshall score were 56, 94.11\%, and 87.34 , $52.63 \%$, respectively, and $57.69,94.44 \%$, and $87.34,52.63 \%$, at 1 month, respectively. ${ }^{15}$ Sensitivity and specificity for mortality prediction at 2 weeks for Rotterdam and Marshall score were 57.69, 94.44\%, and 87.17, 50\%, respectively. ${ }^{15}$ Receiver operating characteristic (ROC) area under the curve (AUC) showed higher accuracy in predicting mortality at 2 weeks, 1 month, and 3 months for Rotterdam score as compared with the Marshall score. ${ }^{15}$ Huang et al evaluated the efficacy of Rotterdam scoring in predicting outcome and mortality after decompressive craniectomy (DC) in TBI. ${ }^{20}$ They reported that Rotterdam score is an independent predictor of unfavorable outcome defined by GOS of 1 to 3, with odds ratio of $1.830,95 \%$ confidence interval of 1.043 to 3.212 , and $p=0.035 . .^{20}$ The study by Huang et $\mathrm{al}^{20}$ highlights an important limitation of Marshall scoring and utility of Rotterdam scoring in prognosticating TBI patients requiring DC. In the study by Huang et al, ${ }^{20} 90 \%$ of patients requiring DC belong 


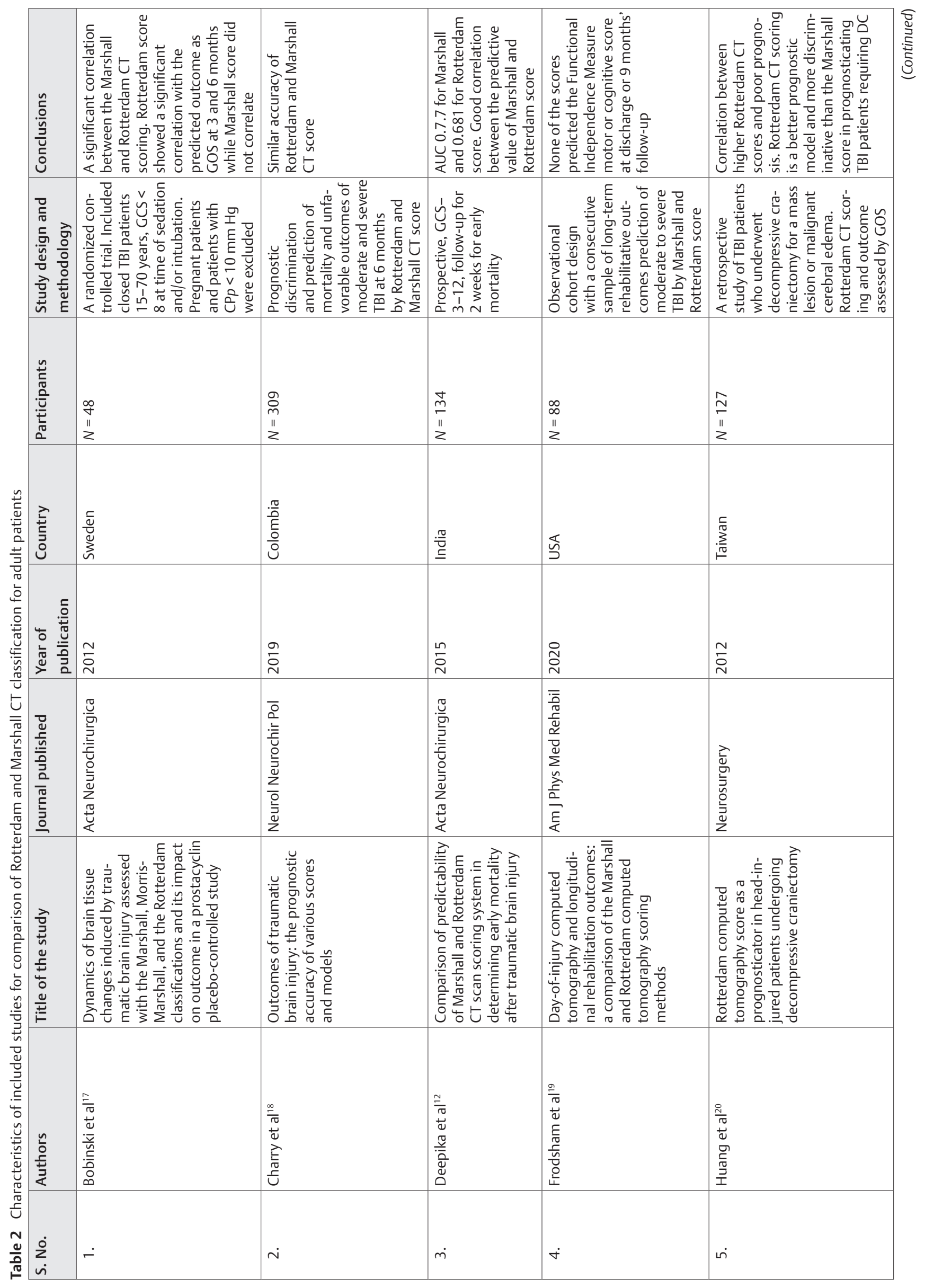

Indian Journal of Neurotrauma Vol. 19 No. 2/2022 $\quad$ @ 2021. Neurotrauma Society of India. 


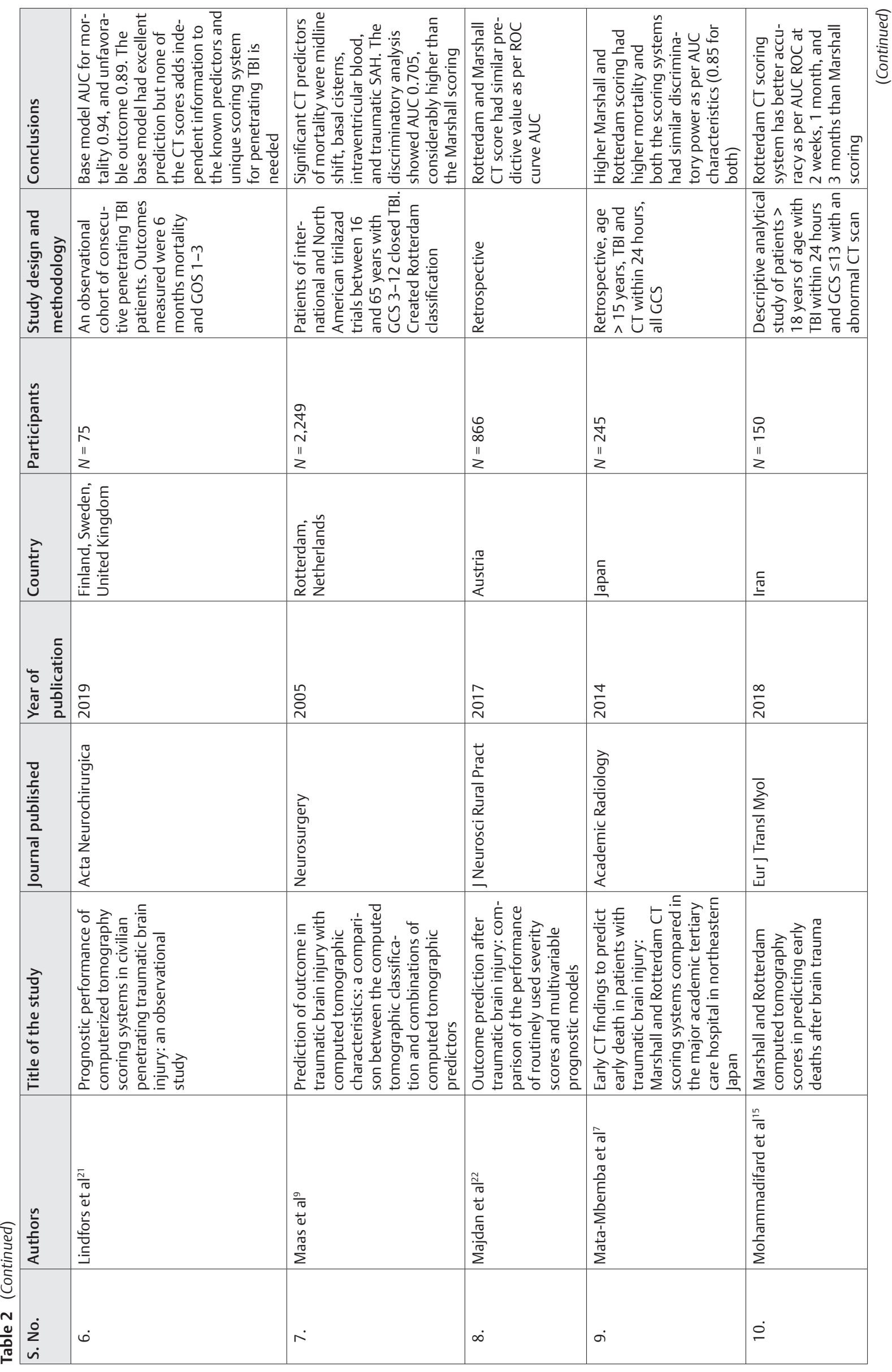




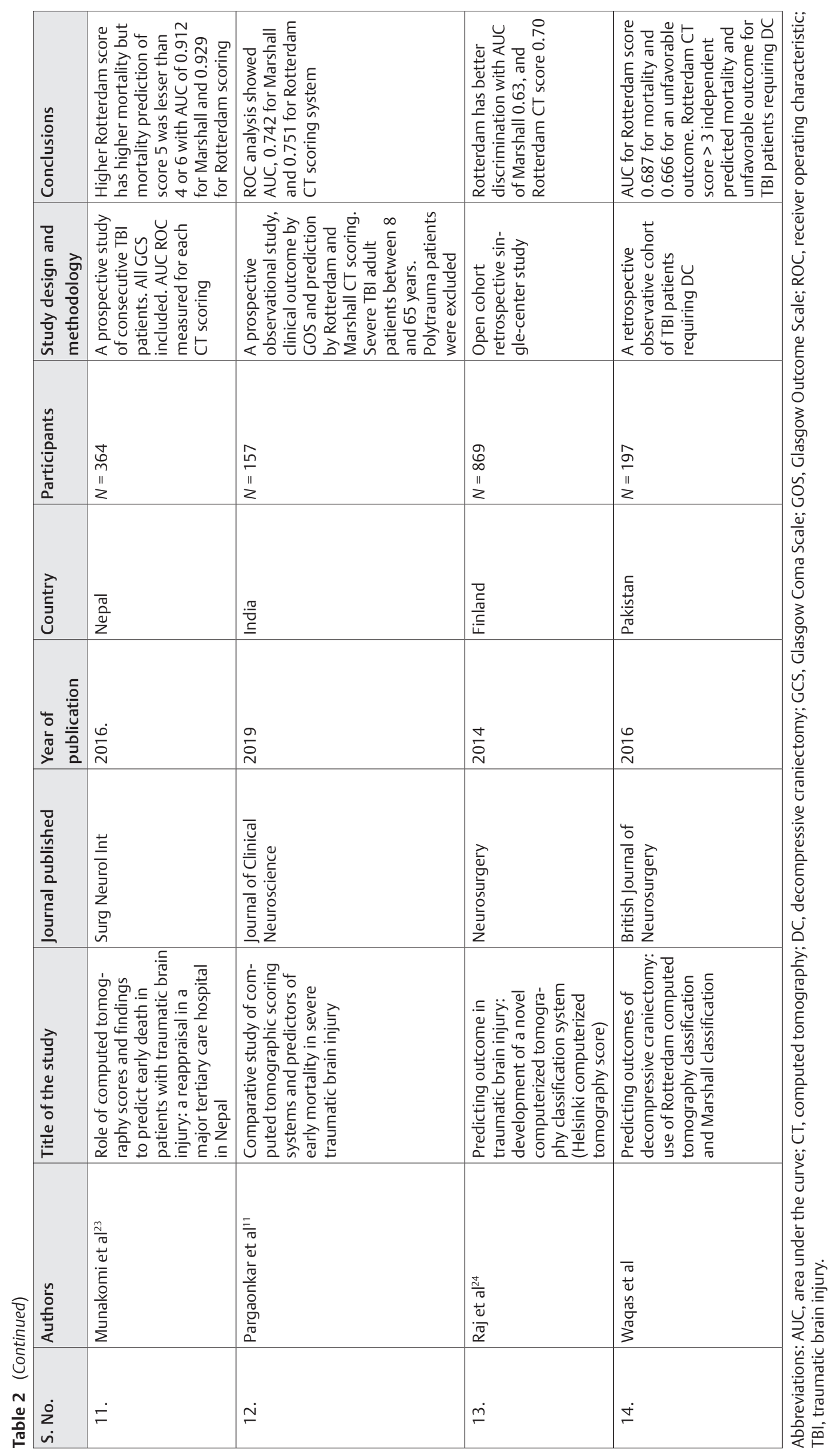

Indian Journal of Neurotrauma Vol. 19 No. 2/2022 $\quad$ c 2021. Neurotrauma Society of India. 
to Marshall class V. In a similar study, Waqas et al found that Rotterdam score has significant independent predictive value for mortality and unfavorable outcome in TBI patients requiring DC. ${ }^{14}$ Therefore, in these patients, Rotterdam CT scoring would have more discriminatory predictive strength. Mass et $\mathrm{al}^{9}$ reported in their study on the efficacy of Marshall CT scoring system, that combination of individual CT findings, additional CT findings like the presence of traumatic SAH, and detailed description of mass lesions predicts outcome better than the Marshall CT scoring system. ${ }^{9}$ In fact, Marshall classification was not intended to be a prognostic model and thus Mass et $\mathrm{al}^{9}$ compared it with a model comprising of individual CT characteristic findings and reported Rotterdam score to be a better prognostic model. In the observational study by Pargaonkar et al, ${ }^{11}$ researchers found that Rotterdam score had a better linear relationship between scoring and mortality than Marshall CT score. Similar findings were obtained in the study by Munakomi et al. ${ }^{23,32}$ Also, the positive predictive value for predicting mortality was higher for Rotterdam scoring (82.5\%) as compared with the Marshall CT scoring system (79.3\%). ${ }^{11}$ Similar results were reported with the highest accuracy for Rotterdam CT score in predicting the outcome based on GOS at 3 and 6 months (AUC 0.722) as compared with the Marshall score (AUC 0.657). ${ }^{17,24}$ Nelson et $\mathrm{al}^{33}$ reported better predictive power of CT characteristics of Rotterdam score than Marshall score in extended analysis of CT scans. They further suggested that the most important parameter in predicting mortality is the magnitude of midline shift which is a continuous variable. ${ }^{33}$

\section{Limitations of the Rotterdam CT Scoring System}

One of the drawbacks of the Rotterdam scoring is that the authors used CT scan performed within first 4 hours of the admission and not the worst CT scan, as worst CT scan is done later which might have better predictive power. Another limitation is that patients with mild head injury were excluded from the study by Mass et $\mathrm{al}^{9}$ and hence Rotterdam CT scoring might not be applied to the prediction in these patients who can have neurological deterioration over time. Since midline shift and status of the basal cisterns are important CT characteristics in Rotterdam score, the inter-rater variability is a concern when a CT scan is evaluated by physicians with different expertise. Studies reported higher interclass correlation for Marshall scoring as compared with the Rotterdam scoring. ${ }^{34,35}$ The classification fails to predict long-term rehabilitation of TBI patients and clinical outcomes in penetrating TBI patients. ${ }^{19}$

\section{Predictive Value of the Marshall CT Scoring System}

Mass et $\mathrm{al}^{9}$ reported good predictive value of Marshall CT scoring model which can be enhanced by combining the individual characteristics. Marshall score is validated, widely used for prediction of mortality, and functional outcome which are lacking in the Rotterdam score. ${ }^{36,37}$ In the study by Deepika et al, ${ }^{12}$ authors found that Rotterdam score had similar accuracy to Marshall score and not superior. Majdan et al compared ROC AUC for the predictive value of Rotterdam and Marshall score and reported similar performance for the two scores. ${ }^{22}$ Similar results were found in another study by Charry et al. ${ }^{18}$ Mata-Mbemba et al reported that Marshall score has as good predictive power as Rotterdam score. ${ }^{7}$ Although Mata-Mbemba et al included a large number of patients, their study has high risk of bias due to concealment of allocation. This could limit the validation of their conclusion. Munakomi et $\mathrm{al}^{23,32}$ highlighted the importance of mortality prediction of Marshall score ( $0 \%$ for 1, 2, and 4, $40 \%$ for 3, $18.79 \%$ for 5 , and $95.66 \%$ for 6 ) and importance of evacuation of mass lesions.

\section{Limitations of the Marshall CT Scoring System}

The problem with Marshall scoring is that it is more descriptive than discriminatory as most of the patients who would require DC belong to Marshall class IV or V and therefore it is not possible to use it as a predictor for mortality in these cases accurately. Marshall CT score is based on data collected between 1984 and 1987 from 753 patients of Traumatic Coma Data Bank, which is much less than the number of patients in the study for the Rotterdam score. ${ }^{10}$ The predictor of hematoma evacuated or nonevacuated can only be applied retrospectively. ${ }^{12}$ The cutoff of $25 \mathrm{~mL}$ is not uniform for the traumatic intracranial lesions as guidelines differ for different pathology. It is expected for the mortality in patients with Marshall grade $\mathrm{V}$ to be lesser than grade IV and $\mathrm{V}$ as it includes evacuated mass lesions..$^{12,32,38}$ Also, in any study patients with Marshall score IV are likely to be less in number as many patients with midline shift may require surgery irrespective of GCS and this practice varies among the surgeons and centers. ${ }^{32}$ The study by Bobinski et al showed that 17 patients had evacuated mass lesions at 24-hour CT who had nonevacuated mass lesion at the initial CT scan. This highlights one very important scenario where prognostication based on Marshall score should be performed with care as the score and predicted outcome can change over time. They further reported that Rotterdam score bears significant negative correlation with GOS based on initial and 24-hour CT scan, but for Marshall score, negative correlation with GOS was found based on initial CT scan and not on CT scan done at 24 hours. ${ }^{17}$ Similar to Rotterdam classification, the classification fails to predict long-term rehabilitation of TBI patients and clinical outcomes in penetrating TBI patients. ${ }^{19}$ Marshall CT scoring is not appropriate as prognostic model for TBI patients requiring DC. ${ }^{14,20}$

\section{Rotterdam and Marshall Scoring in Pediatric TBI Patients}

Marshall and Rotterdam CT scoring has not been validated in patients aged $<14$ years. ${ }^{7}$ Rotterdam scoring is used to predict unfavorable outcome in pediatric populations, results were different from the adult population. ${ }^{13}$ Pediatric population had better outcomes for the same scoring in less severe injuries but worse outcomes in cases of more severe injuries for the same scoring in adults. ${ }^{13}$ All the patients with Rotterdam score of 6 had GCS 3 and 22\% of the patients with Rotterdam score of 2 , that is, normal scans, had GCS of $3 .^{13}$ 
As a result, they suggested modification in Rotterdam score for better accuracy in the pediatric age group as predicted mortality $=\left[\mathrm{e}^{-6.57+\left(1.527^{*} \text { Rotterdam }\right)}\right] /\left[1+\mathrm{e}^{-6.57+\left(1.527^{*} \text { Rotterdam }\right)}\right] \cdot{ }^{13}$ Higher mortality (odds ratio 1.75) was found to be associated with higher Rotterdam score in a prospective observational cohort of 92 pediatric patients with age range of 1 month to 6 years suggesting that Rotterdam score can be used to predict mortality in pediatric patients. ${ }^{39}$ Contrary to this, Mikkonen et $\mathrm{al}^{40}$ reported that adult CT scoring system performs well in a retrospective cohort of 341 TBI patients aged < 18 years treated in the intensive care unit, with Rotterdam score having better predictive value (AUC 0.80) than Marshall score. Talari et $\mathrm{al}^{41}$ reported in a retrospective cohort of 506 pediatric patients of the suitability of Rotterdam score cutoff of 3 for predicting early mortality and clinical outcome with acceptable sensitivity and specificity. ROC AUC to delineate the strength in predicting survival in pediatric patients was 0.838 and 0.781 and for GOS $\leq 3$ was 0.748 and 0.663 for Rotterdam and Marshall CT score. ${ }^{42}$ Similar results were found for the Rotterdam score in other studies. ${ }^{43}$

\section{Limitation of Current Systematic Review and Meta-Analysis}

The present study was conducted based on individual variables and their association with the outcome. This resulted in a different number of studies for each variable. The other drawback of the present study is noninclusion of different variables that can affect the outcome after TBI. Intracranial pressure data, cerebral perfusion pressure data, and treatment information can influence the outcome and mortality after TBI. The time frame for data collection and observation is also variable in individual studies. Since the majority of studies included in the review are retrospective in nature with a variable time of outcome assessment. For prognostic models, the outcome should be assessed at a fixed point of time. Further lack of information on intracranial pressure and prognostic effects of individual characteristics in the CT scan adds to the relative weaknesses of this review. Another limitation of our study is that the endpoint defined is mortality risk stratification rather than other functional outcome variables. This is because we believe that mortality would be an objective endpoint with no inter-rater variability and missing outcome. Most of the studies have reported comparative analysis of the two scoring systems based on initial CT scans, moderate and severe TBI patients, and mortality outcomes at 6 months. This cannot be generalized for a wider cohort of mild TBI patients, geriatric, and pediatric patients. ${ }^{13,44}$ Also, there is likely an evolution of CT changes which may have a better prediction. It is needless to mention that 6 months is a long time and many factors may confound the measured outcome of mortality, therefore some authors have suggested using these CT scores for early mortality prediction, preferable within 1 or 2 weeks. ${ }^{12,45}$

\section{Conclusion}

A combination of clinical parameters, severity, ischemic and hemodynamic parameters, and CT scoring system could predict the prognosis of TBI patients with significant accuracy. Marshall scoring is more descriptive, widely accepted with good predictive value, and good inter-rater reliability, and Rotterdam score is superior in the description of dynamics of intracranial changes. Though most of the studies concluded that Rotterdam CT scoring is better than the Marshall CT scoring, we believe that the two scoring systems are complimentary. As either of the scoring systems has its limitations and Rotterdam CT scoring system improvises upon Marshall CT scoring, a combination approach would yield a better predictive model. The predictive power of Rotterdam score is different in the pediatric age group as compared with adults and modifications are required for better applicability of CT-based scoring system in the pediatric age group. Further prospective comparative studies in mild TBI patients, pediatric, and geriatric TBI patients are required to establish their wider applicability.

Conflict of Interest

None declared.

\section{References}

1 Rubiano AM, Carney N, Chesnut R, Puyana JC. Global neurotrauma research challenges and opportunities. Nature 2015; 527(7578) :S193-S197

2 Agrawal A, Savardekar A, Singh M, et al. Pattern of reporting and practices for the management of traumatic brain injury: an overview of published literature from India. Neurol India 2018;66(4):976-1002

3 Global Burden of Disease Study 2013 Collaborators. Global, regional, and national incidence, prevalence, and years lived with disability for 301 acute and chronic diseases and injuries in 188 countries, 1990-2013: a systematic analysis for the Global Burden of Disease Study 2013. Lancet 2015;386(9995): 743-800

4 Maas AI, Stocchetti N, Bullock R. Moderate and severe traumatic brain injury in adults. Lancet Neurol 2008;7(8):728-741

5 Charry JD, Falla JD, Ochoa JD, et al. External validation of the Rotterdam computed tomography score in the prediction of mortality in severe traumatic brain injury. J Neurosci Rural Pract 2017;8(Suppl 1) :S23-S26

6 Perel P, Edwards P, Wentz R, Roberts I. Systematic review of prognostic models in traumatic brain injury. BMC Med Inform Decis Mak 2006;6:38

7 Mata-Mbemba D, Mugikura S, Nakagawa A, et al. Early CT findings to predict early death in patients with traumatic brain injury: Marshall and Rotterdam CT scoring systems compared in the major academic tertiary care hospital in northeastern Japan. Acad Radiol 2014;21(5):605-611

8 Murray GD, Butcher I, McHugh GS, et al. Multivariable prognostic analysis in traumatic brain injury: results from the IMPACT study. J Neurotrauma 2007;24(2):329-337

9 Maas AI, Hukkelhoven CW, Marshall LF, Steyerberg EW. Prediction of outcome in traumatic brain injury with computed tomographic characteristics: a comparison between the computed tomographic classification and combinations of computed tomographic predictors. Neurosurgery 2005;57(6):1173-1182, discussion 1173-1182

10 Marshall LF, Marshall SB, Klauber MR, et al. The diagnosis of head injury requires a classification based on computed axial tomography. J Neurotrauma 1992;9(Suppl 1) :S287-S292

11 Pargaonkar R, Kumar V, Menon G, Hegde A. Comparative study of computed tomographic scoring systems and predictors of 
early mortality in severe traumatic brain injury. J Clin Neurosci 2019;66:100-106

12 Deepika A, Prabhuraj AR, Saikia A, Shukla D. Comparison of predictability of Marshall and Rotterdam CT scan scoring system in determining early mortality after traumatic brain injury. Acta Neurochir (Wien) 2015;157(11):2033-2038

13 Liesemer K, Riva-Cambrin J, Bennett KS, et al. Use of Rotterdam CT scores for mortality risk stratification in children with traumatic brain injury. Pediatr Crit Care Med 2014;15(6):554-562

14 Waqas M, Shamim MS, Enam SF, et al. Predicting outcomes of decompressive craniectomy: use of Rotterdam computed tomography classification and Marshall classification. $\mathrm{Br} \mathrm{J}$ Neurosurg 2016;30(2):258-263

15 Mohammadifard M, Ghaemi K, Hanif H, Sharifzadeh G, Haghparast M. Marshall and Rotterdam computed tomography scores in predicting early deaths after brain trauma. Eur J Transl Myol 2018;28(3):7542

16 Liberati A, Altman DG, Tetzlaff J, et al. The PRISMA statement for reporting systematic reviews and meta-analyses of studies that evaluate health care interventions: explanation and elaboration. PLoS Med 2009;6(7):e1000100

17 Bobinski L, Olivecrona M, Koskinen LO. Dynamics of brain tissue changes induced by traumatic brain injury assessed with the Marshall, Morris-Marshall, and the Rotterdam classifications and its impact on outcome in a prostacyclin placebo-controlled study. Acta Neurochir (Wien) 2012;154(6):1069-1079

18 Charry JD, Navarro-Parra S, Solano J, Moscote-Salazar L, Pinzón MA, Tejada JH. Outcomes of traumatic brain injury: the prognostic accuracy of various scores and models. Neurol Neurochir Pol 2019;53(1):55-60

19 Frodsham KM, Fair JE, Frost RB, et al. Day-of-injury computed tomography and longitudinal rehabilitation outcomes: a comparison of the Marshall and Rotterdam computed tomography scoring methods. Am J Phys Med Rehabil 2020;99(9):821-829

20 Huang YH, Deng YH, Lee TC, Chen WF. Rotterdam computed tomography score as a prognosticator in head-injured patients undergoing decompressive craniectomy. Neurosurgery 2012;71(1):80-85

21 Lindfors M, Lindblad C, Nelson DW, et al. Prognostic performance of computerized tomography scoring systems in civilian penetrating traumatic brain injury: an observational study. Acta Neurochir (Wien) 2019;161(12):2467-2478

22 Majdan M, Brazinova A, Rusnak M, Leitgeb J. Outcome prediction after traumatic brain injury: comparison of the performance of routinely used severity scores and multivariable prognostic models. J Neurosci Rural Pract 2017;8(1):20-29

23 Munakomi S, Bhattarai B, Srinivas B, Cherian I. Role of computed tomography scores and findings to predict early death in patients with traumatic brain injury: a reappraisal in a major tertiary care hospital in Nepal. Surg Neurol Int 2016;7:23

24 Raj R, Siironen J, Skrifvars MB, Hernesniemi J, Kivisaari R. Predicting outcome in traumatic brain injury: development of a novel computerized tomography classification system (Helsinki computerized tomography score) Neurosurgery 2014;75(6):632-646, discussion 646-647

25 Malec JF, Brown AW, Leibson CL, et al. The Mayo classification system for traumatic brain injury severity. J Neurotrauma 2007;24(9):1417-1424

26 Jennett B, Bond M. Assessment of outcome after severe brain damage. Lancet 1975;1(7905):480-484

27 Teasdale G, Jennett B. Assessment of coma and impaired consciousness. A practical scale. Lancet 1974;2(7872):81-84

28 Mishra RK, Munivenkatappa A, Prathyusha V, Shukla DP, Devi BI. Clinical predictors of abnormal head computed tomography scan in patients who are conscious after head injury. J Neurosci Rural Pract 2017;8(1):64-67

29 Marshall LF, Marshall SB, Klauber MR, et al. A new classification of head injury based on computerized tomography. J Neurosurg 1991;75:S14

30 Chesnut RM. Management and prognosis of severe traumatic brain injury. Part 2. Early indicators of prognosis in severe traumatic brain injury. J Neurotrauma 2000;17:557-627

31 Lobato RD, Gomez PA, Alday R, et al. Sequential computerized tomography changes and related final outcome in severe head injury patients. Acta Neurochir (Wien) 1997;139(5):385-391

32 Munakomi S. A comparative study between Marshall and Rotterdam CT scores in predicting early deaths in patients with traumatic brain injury in a major tertiary care hospital in Nepal. Chin J Traumatol 2016;19(1):25-27

33 Nelson DW, Nyström H, MacCallum RM, et al. Extended analysis of early computed tomography scans of traumatic brain injured patients and relations to outcome. J Neurotrauma 2010;27(1):51-64

34 Chun KA, Manley GT, Stiver SI, et al. Interobserver variability in the assessment of CT imaging features of traumatic brain injury. J Neurotrauma 2010;27(2):325-330

35 Creeden S, Ding VY, Parker JJ, et al. Interobserver agreement for the computed tomography severity grading scales for acute traumatic brain injury.J Neurotrauma 2020;37(12):1445-1451

36 Bullock MRCR, Ghajar J, Gordon D, et al. Guidelines for the surgical management of traumatic brain injury. Neurosurgery 2006;58(Supplement):S2-S62

37 Perel P, Arango M, Clayton T, et al; MRC CRASH Trial Collaborators. Predicting outcome after traumatic brain injury: practical prognostic models based on large cohort of international patients. BMJ 2008;336(7641) :425-429

38 Thelin EP, Nelson DW, Vehviläinen J, et al. Evaluation of novel computerized tomography scoring systems in human traumatic brain injury: an observational, multicenter study. PLoS Med 2017;14(8):e1002368

39 Haque A, Dhanani Z, Ali A, et al. Outcome of traumatic brain injury in children by using Rotterdam score on computed tomography. J Ayub Med Coll Abbottabad 2018;30(1):140-142

40 Mikkonen ED, Skrifvars MB, Reinikainen M, et al. Validation of prognostic models in intensive care unit-treated pediatric traumatic brain injury patients. J Neurosurg Pediatr 2019:1-8

41 Talari HR, Hamidian Y, Moussavi N, et al. The prognostic value of Rotterdam computed tomography score in predicting early outcomes among children with traumatic brain injury. World Neurosurg 2019;125:e139-e145

42 Hale AT, Stonko DP, Brown A, et al. Machine-learning analysis outperforms conventional statistical models and CT classification systems in predicting 6-month outcomes in pediatric patients sustaining traumatic brain injury. Neurosurg Focus 2018;45(5):E2

43 Katar S, Aydin Ozturk P, Ozel M, et al. The use of Rotterdam CT score for prediction of outcomes in pediatric traumatic brain injury patients admitted to emergency service. Pediatr Neurosurg 2020;55(5):237-243

44 Garza N, Toussi A, Wilson M, Shahlaie K, Martin R. The increasing age of TBI patients at a single level 1 trauma center and the discordance between GCS and CT Rotterdam scores in the elderly. Front Neurol 2020;11:112

45 Tjahjadi M, Arifin MZ, Gill AS, Faried A. Early mortality predictor of severe traumatic brain injury: a single center study of prognostic variables based on admission characteristics. Indian J Neurotrauma 2013;10:3-8 